\title{
Effect of Tetracycline on Leucocyte Ascorbic Acid Levels
}

\author{
A. C. M. WINDSOR,
}

C. B. HOBBS,

D. A. TREBY,

British Medical fournal, 1972, 1, 214-215

\section{Summary}

Fourteen men aged 73-94 showed a fall in leucocyte ascorbic acid levels during five days' treatment with $1 \mathrm{~g}$ of tetracycline daily. A control group of nine men aged 74-90 showed no fall in leucocyte ascorbic acid levels. Of the control group, three were treated with phenobarbitone $60 \mathrm{mg}$ thrice daily, three with phenylbutazone $200 \mathrm{mg}$ thrice daily, and three with aloxiprin 1,200 mg four times a day. A further two men aged 87 and 90 showed increased urinary excretion of ascorbic acid while receiving $1 \mathrm{~g}$ of tetracycline daily.

\section{Introduction}

Many factors are known to be associated with low leucocyte ascorbic acid levels. Cohen and Duncan (1967) showed that patients with duodenal ulcer and gastrointestinal disease have low levels. The vitamin C concentration in leucocytes is also lowered in smokers (Brook and Grimshaw, 1968) and in patients with cancer and non-cancerous chronic disease (Bodansky et al., 1952). The elderly are particularly prone to have low leucocyte ascorbic acid levels (Denson and Bowers, 1961; Andrews et al., 1966) and are vulnerable to factors increasing ascorbic acid excretion, since Otswald (1959) found that the need for ascorbic acid as an oxidation-reduction factor increases with age. The interrelationship between drug therapy and ascorbic acid metabolism has not been fully investigated in the human being though it is known that various drugs such as Chloretone, phenylbutazone, sulphinpyrazone, and chlorcyclizine stimulate markedly the urinary excretion of L-ascorbic acid in rats (Conney et al., 1961). Richards et al. (1941) reported that vitamin-C-deficient guinea-pigs were more sensitive than normal guinea-pigs to pentobarbitone.

It has been suggested that antibiotics may induce vitamin deficiency by competitive blockage of intracellular metabolism (Goldsmith, 1956), and Milberg et al. (1955) used tetracycline combined with water-soluble vitamins. It was therefore considered worth while to study the effect of tetracycline on ascorbic acid metabolism particularly in view of the fact that Shah et al. (1968) suggested that tetracycline causes a depletion of ascorbic acid in the buffy coat and serum.

\section{Method}

The patients in the study, all volunteers, were thoroughly examined for clinical signs of hypovitaminosis before and after treatment. During the study they were on normal ward diet

\section{Bristol General Hospital, Bristol}

A. C. M. WINDSOR, M.R.C.P., Consultant Geriatrician

Bath Clinical Area

C. B. HOBBS, M.R.C.PATH., Consultant Chemical Pathologist

Royal United Hospital, Bath

D. A. TREBY, A.I.M.L.T., Research Assistant

St. Martin's Hospital, Bath

R. ASTLEY COWPER M.B., B.CH., Senior House Officer, Geriatrics

\author{
R. ASTLEY COWPER
}

with no added vitamin supplements or citrus fruits. No signs of vitamin deficiency were found.

Fourteen men aged 73-94 years had daily estimates of leucocyte ascorbic acid levels before, during, and after treatment with tetracycline $250 \mathrm{mg}$ four times a day for five days. Of the control group of patients (age 74-90), three received aloxiprin (Palaprin Forte) 1,200 mg four times a day, three were treated with phenobarbitone $60 \mathrm{mg}$ thrice daily, and three with butazolidine $200 \mathrm{mg}$ thrice daily for five days. A further two men aged 87 and 90 had urinary ascorbic acid levels estimated in addition to leucocyte ascorbic acid levels before, during, and after treatment with tetracycline $250 \mathrm{mg}$ four times daily for five days. The leucocyte ascorbic acid levels were estimated by the method of Denson and Bowers (1961) and urinary ascorbic acid was estimated by the method of Harris and Ray (1935).

\section{Results}

Fig. 1 indicates that there is a decrease in leucocyte ascorbic acid levels during treatment with tetracycline. The decrease

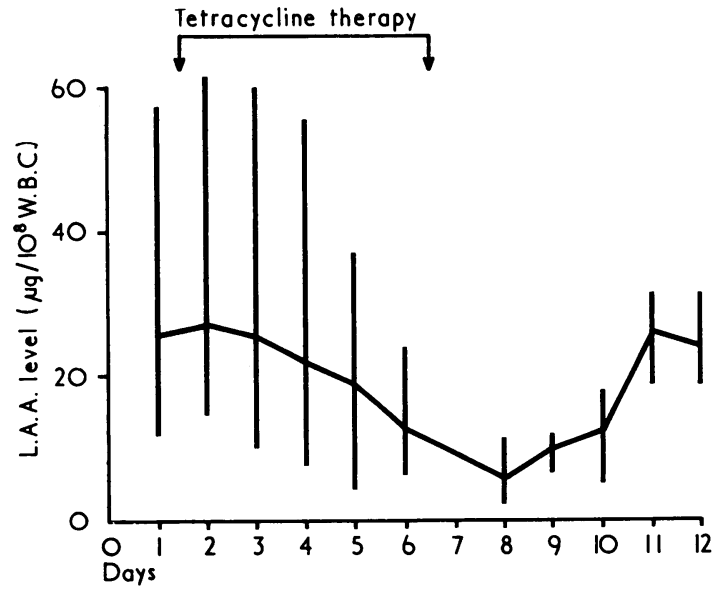

FIG. 1-Effect of tetracycline on mean and range of leucocyte ascorbic acid levels in 14 men (age 73-94 years).

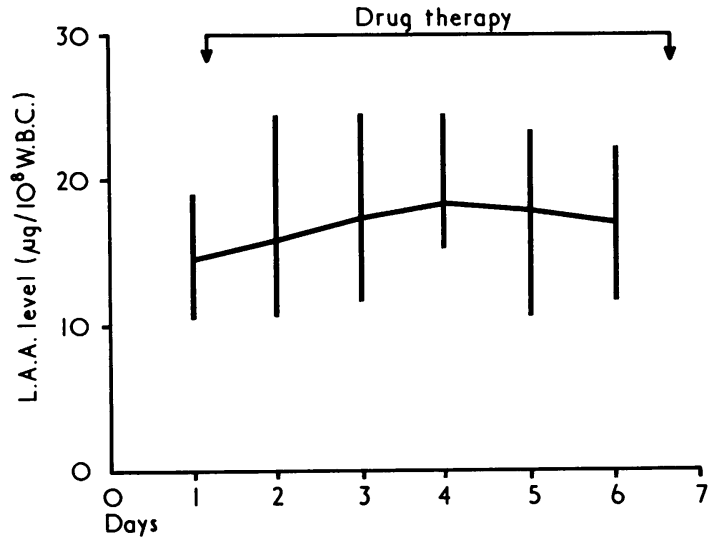

FIG. 2-Mean and range of leucocyte ascorbic acid levels in control groups of 9 men (age range 74-90 years), three of whom were treated with phenobarbitone, three with butazolidine, and three with aloxiprin. 
occurred in all the cases by the fourth day of treatment and was to at least $50 \%$ below the pretreatment levels. Fig 2 gives the levels in the controls. Figs. 3 and 4 show that an increase in urinary excretion of ascorbic acid accompanies the decreased leucocyte ascorbic acid levels during tetracycline therapy.

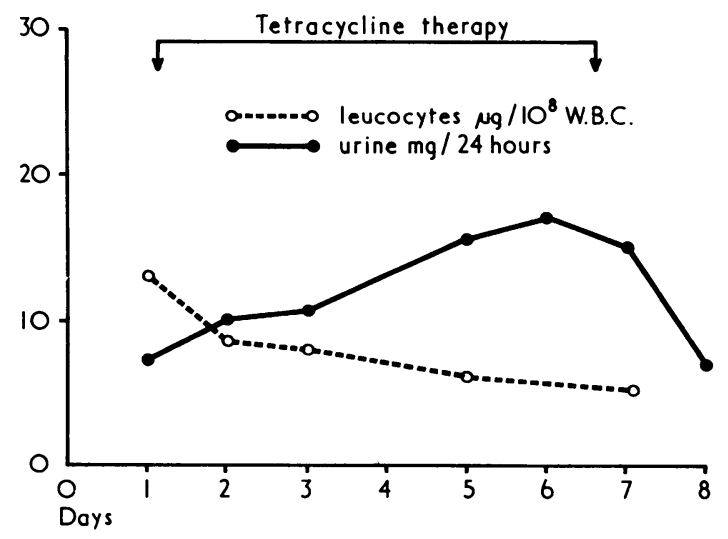

FIG. 3-Effect of tetracycline on ascorbic acid levels in urine and leucocytes of man aged 90.

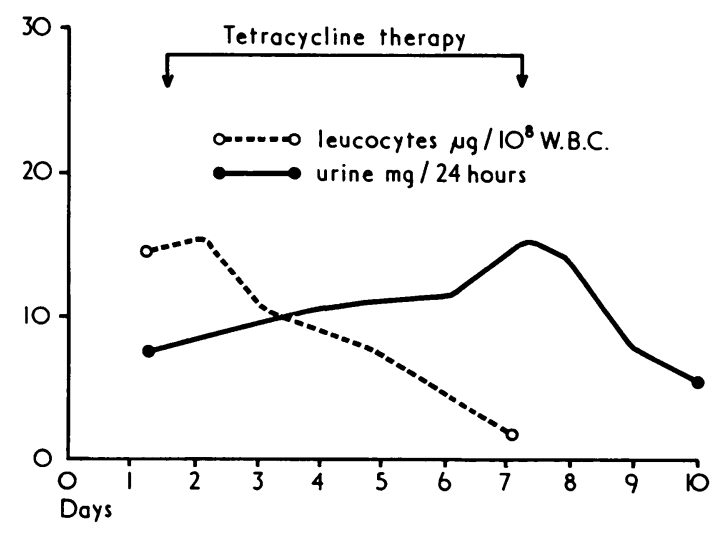

FIG. 4-Effect of tetracycline on urine and leucocyte ascorbic acid levels in man aged 87.

\section{Discussion}

It is of interest that aloxiprin caused no fall in leucocyte ascorbic acid level though it has been observed that high dosage of soluble aspirin results in lowering of platelet ascorbic acid levels (Sahud and Cohen, 1971). The dose of soluble aspirin used, however, was much higher and given for a larger period of time.

The findings with tetracycline are similar to those of Shah et al. (1968), who observed that tetracycline therapy over a four-day period leads to a significant depletion of ascorbic acid by the third day in the buffy coat and by the fourth day in the serum. The present results, however, have shown an increased urinary excretion of vitamin $C$ during tetracycline therapy. The reason for this finding is unknown but it may be due to blocking of renal tubular reabsorption of ascorbic acid by the antibiotic. Tetracycline also acts as a catalyst in the degradation of ascorbic acid to dehydroascorbic acid (Dudani and Krishnanurti, 1954). The antibiotic activity and fluorescent property of tetracycline are not altered by its catalysis of ascorbic acid oxidation.

Munoz and Geister (1950) noticed that chlortetracycline inhibited phagocytosis. Nungster and Ames (1948) showed that the phagocytic activity of the polymorphonuclear leucocytes in peritoneal exudates was related to the ascorbic acid content of the leucocytes. Thus tetracycline may well owe its inhibition of phagocytic activity to its action of depleting the leucocytes of ascorbic acid. Tetracycline has also been shown to cause a reduction in serum $B_{12}, B_{6}$, and pantothenic acid levels (Bremenep et al, 1967). It would therefore seem that long-term therapy with tetracycline could cause serious vitamin depletion, particularly in the elderly.

This work was performed with the aid of a grant by Roche Products Ltd.

\section{References}

Andrews, J., Brook, M., and Allen, M. A. (1966). Gerontologia Clinica, 8, 257 Bodansky, O., Wroblewski, F., and Markardt, B. (1952). Cancer (Philadelphia), 5, 678.

Bremenep, S. M., et al. (1967). Antibiotiki, 12, 343.

Brook, M., and Grimshaw, J. J. (1968). American fournal of Clinical Nutrition, 21, 1254

Cohen, M. M., and Duncan, A. M. (1967). British Medical fournal, 4, 516 Conney, A. H., Bray, G. A., Evans, C., and Burns, J. J. (1961). Annals of the New York Academy of Sciences, 92, 115

Denson, K. W., and Bowers, E. F. (1961). Clinical Science, 21, 157

Dudani, A. T., and Krishnanurti, C. R. (1954). Biochimica et Biophysica Acta, 13, 505

Goldsmith, G. A. (1956). New England fournal of Medicine, 254, 165.

Harris, L. J., and Ray, S. M. (1935). Lancet, 1, 462.

Milberg, M. B., Schweatz, R. D., and Michael, M. J. (1956). Antibiotics Annual (1955-56), 298.

Munoz, J., and Geister, R. (1950). Proceedings of the Society for Experimental Biology and Medicine, 75, 367.

Nungster, W. J., and Ames, A. M. (1948). Fournal of Infectious Diseases, 83, 50

Otswald, E., (1959). Ärztliche Praxis, 11, 3.

Richards, R. K., Kuster, K., and Klatt, T. J. (1941). Proceedings of the Society for Experimental Biology and Medicine, 48, 403.

Sahud, M. A., and Cohen, R. J. (1971). Lancet, 1, 937.

Shah, K. V., Barbhaiya, H. C., and Skrinwasan, V. (1968). Fournal of the Indian Medical Association, 51, 127. 